\title{
ESTUDO DO POTENCIAL DE FUNGOS ENDOFÍTICOS NO CONTROLE DO AGENTE CAUSAL DA FUSARIOSE EM TOMATEIRO
}

\author{
Kellem Ângela Oliveira de Sousa ${ }^{1}$; José Fábio França de Orlanda²; Gustavo de \\ Andrade Bezerra ${ }^{1}$; Thatyane Pereira de Sousa ${ }^{3}$. \\ ${ }^{1}$ Graduandos do curso de Engenharia Agronômica da Universidade Estadual do Maranhão (UEMA). Imperatriz, \\ Maranhão, Brasil.guandrade.b@gmail.com \\ 2 Professor, Doutor da UEMA. Imperatriz, Maranhão, Brasil. \\ ${ }^{3}$ Mestranda em Agronomia da Universidade Federal Rural da Amazônia. Belém, Pará, Brasil.
}

\begin{abstract}
RESUMO: O presente trabalho objetivou avaliar a capacidade antimicrobiana in vitro, de diferentes extratos de fungos endofíticos, como alternativa no biocontrole de Fusarium oxysporum f.sp. lycopersici. Foram obtidos oito isolados endofíticos de plantas do Cerrado Maranhense e de interesse econômico, a saber: aroeira (Myracrodruon urundeuva Allemão), jenipapo (Genipa americana L.), milho (Zea Mays L.), mandioca (Manihot esculenta Crantz), vinagreira (Hibiscus sabidariffa L.) e graviola (Annona muricata L.). Os isolados endofiticos das espécies foram identificados em Aspergillus niger e Penicillium italicum, com características morfológicas distintas entre as colônias e todos os isolados endofíticos verificou-se crescimento mediano. Para a atividade antimicrobiana, foi realizada a extração dos metabólitos dos isolados endofiticos com os solventes: Acetato de Etila, Clorofórmio e Diclorometano, posteriormente realizado o bioensaio através do confronto direto do antagonista (endófito) sobre o Fusarium Oxysporum f.sp. lycopersici, raça 1, pelo método de difusão em ágar. Os extratos dos isolados endofíticos obtidos do solvente Clorofórmio apresentaram capacidade inibitória, assim interferindo no crescimento do Fusarium oxysporum f. sp. lycopersici raça. Que foram provenientes do caule milho (II) e de jenipapo, com diâmetros de $13 \mathrm{~mm}$ e $11 \mathrm{~mm}$, respectivamente, os outros extratos dos isolados apresentaram halos de inibição inferior.
\end{abstract}

PALAVRAS-CHAVE: antibiose, controle biológico, fitopatógeno.

\section{STUDY OF POTENTIAL ENDOPHYTES IN CONTROL OF THE CAUSAL AGENT IN TOMATO FUSARIOSIS}

\begin{abstract}
This study aimed to evaluate the ability antimicrobial in vitro of different extracts of endophytic fungi as an alternative in biocontrol of Fusarium oxysporum f.sp. lycopersici. Eight endophytic isolates were obtained from plants of the Cerrado Maranhense and economic interest, namely: mastic (Myracrodruon urundeuva Allemão), jenipapo (Genipa americana L.), maize (Zea Mays L.), cassava (Manihot esculenta Crantz), vinegar (Hibiscus sabidariffa L.) and soursop (Annona muricata L.). The isolated endophytic species were identified in Aspergillus niger and Penicillium italicum, with distinct morphological characteristics between the colonies and all endophytic growth medium was found. Antimicrobial activity was performed to extract the metabolites of endophytic isolates with solvents: Ethyl Acetate, Chloroform and Dichloromethane subsequently performed bioassay through direct confrontation of the antagonist (endophyte) on Fusarium oxysporum f.sp. lycopersici race 1, by agar diffusion method. The extracts of endophytic isolates obtained from solvent Chloroform showed inhibitory capacity, thus interfering with the growth of
\end{abstract}


Fusarium oxysporum f. sp. lycopersici race 1 were derived stem corn (II) and jenipapo with diameters of $13 \mathrm{~mm}$ and $11 \mathrm{~mm}$, respectively, the other extracts of the isolates showed inhibition halos below.

KEYWORD: antibiosis, biological control, plant pathogen.

O tomateiro (Solanum lycopersicum L.) é uma das hortaliças mais cultivadas e consumidas no mundo e considerada uma cultura de grande importância econômica (FERNANDES et al., 2007; CARVALHO et al., 2002).

Por ser uma das culturas mais cultivadas no Brasil, estando distribuída em quase todos os estados, a plantação de tomate está sujeita ao ataque de uma grande diversidade de patógenos microbianos. Os fungos são os maiores responsáveis pelas doenças que ocorrem no tomateiro (LOPES; SANTOS, 1994).

Dentre as doenças, a murcha-defusário, causada pelo fungo Fusarium oxysporium f. sp. lycopersici, é umas das doenças mais importantes e disseminada na maioria dos países onde o tomateiro é cultivado (KUROZAWA; PAVAN, 1997).

Como alternativa ao uso de agroquímicos, o controle biológico de fitopatógenos tem se apresentado como uma forma promissora e viável, por meio do uso de microrganismos como agentes protetores de plantas cultivadas (KUNOH, 2002).

Tendo em vista o potencial dos fungos endofíticos como possibilidade no controle biológico, este trabalho tem como objetivo avaliar a capacidade antimicrobiana in vitro de diferentes extratos de fungos endofíticos no biocontrole de Fusarium oxysporum f. sp. lycopersici.

As amostras de espécies vegetais foram coletadas em área do município de Governador Edson Lobão (MA), situado na Região Tocantina, realizadas no período da manhã, entre os meses de março e abril de 2011.

Após as coletas, as amostras foram devidamente armazenadas e encaminhadas para o Laboratório de Biotecnologia Ambiental (LABITEC) da Universidade Estadual do Maranhão, campus de Imperatriz. As espécies coletadas foram: milho (Zea Mays L.), mandioca (Manihot esculenta), graviola (Annona muricata L.), aroeira (Myracrodruon urundeuva Allemão), jenipapo (Genipa americana L.) e vinagreira (Hibiscus sabidariffa), todas apresentando tecidos e órgãos aparentemente sadios, sem qualquer sintoma de doenças.

A esterilização e isolamento dos microrganismos foram realizados de acordo com a metodologia adotada por Souza et al. (2004). 
Os fungos endofíticos isolados, em meio de cultura padrão contendo Batata, Dextrose e Ágar (BDA), foram mantidos em temperatura ambiente e periodicamente avaliados visualmente quanto ao desenvolvimento do micélio vegetativo aéreo. A identificação dos isolados foi feita com base na morfologia de suas estruturas vegetativas e reprodutivas de acordo com chaves de identificação encontradas na literatura específica, descrito por Barnett e Hunter (1987).

Os extratos brutos dos fungos endofíticos que inibiram os patógenos nos ensaios de antagonismo, utilizando o solvente orgânico (acetato de etila, clorofórmio e diclorometano) foram utilizados para extração dos metabólitos secundários.

O antagonismo dos fungos endófitos isolados de plantas foi realizado pelo método da cultura pareada, ou simplesmente pareamento, que consistiu no confronto direto do antagonista (endófito) e do fungo patogênico de interesse agronômico em placas de Petri contendo meio de cultura sólido (MARIANO, 1993).

O método de difusão em ágar é um dos mais simples e confiáveis métodos par teste da susceptibilidade antimicrobiana. Neste método, pequenos discos de filtro de $6 \mathrm{~mm}$ impregnados de extratos de fungos endofíticos são dispostos numa placa de Petri com meio de cultura BDA inoculada com
Fusarium oxysporum f.sp. lycopersici. As placas foram incubadas por 24 horas a $28{ }^{\circ} \mathrm{C}$. Após o período de incubação, os diâmetros das zonas de inibição de crescimento ao redor de cada disco antimicrobiano foram medidos para verificar a susceptibilidade de cada extrato. Os resultados obtidos foram comparados com medidas de diâmetro de zonas, caso houvesse a inibição, em milímetros, de acordo com critérios interpretativos de tabelas publicadas pelo órgão National Committee For Clinical Laboratory Standard (NCCLS, 2002).

Das seis espécies vegetais em estudo, foram isoladas no total oito fungos endofíticos de tecidos e órgãos aparentemente sadios (sete nos caules e um na folha). Destes oito isolados, três fungos endofíticos foram isolados do milho (dois endofíticos do caule e um endofítico da folha), um do caule da mandioca, um do caule da graviola, um do caule da aroeira, um do caule do jenipapo e um do caule da vinagreira.

Alguns fungos demonstram certa especificidade por determinados órgãos vegetais (CLAY; SCHARDL, 2002) De acordo com Felizardo (2005), trabalhando com Licnophora pinaster (arnica mineira) verificou a presença de Glomerella cingulata apenas em amostras provenientes das folhas. 
Dos oito isolados endofíticos, seis colônias apresentaram micélios aéreos com aspecto algodonoso, presença de grânulos e de coloração de cor negra e duas colônias de coloração verde oliva, micélio apresentado textura carmuçada sem presença de grânulos, observados em caule do jenipapo e caule do milho.

Neste trabalho foram identificadas duas espécies de isolados endofítícos: Aspergillus niger e Penicillium italicum, pertecentes ao filo Ascomicota.

$\mathrm{O}$ Aspergillus niger predominou nas seguintes espécies vegetais: milho (caule I e folha), mandioca (caule); vinagreira (caule), graviola (caule) e aroeira (caule). O fungo Penicillium italicum predominou nas espécies jenipapo (caule) e milho (caule II).

A extração dos metabólitos secundários dos isolados endofíticos foram obtidos a partir dos solventes acetato de etila, clorofórmio e diclorometano.

De acordo com a Tabela 1 os resultados mostraram que somente no extrato empregando o solvente clorofórmio houve a presença de picos de absorção máxima entre os comprimentos de onda de 230 a 360 ๆm, indicando a presença de compostos com grupamentos químicos fenólicos.

Tabela 1. Análise espectrofotométrica dos extratos de fungos endofíticos em diferentes solventes.

\begin{tabular}{cccc}
\hline & & \multicolumn{2}{c}{ Comprimentos de Onda (nm) } \\
Isolados & Acetato de Etila & Clorofórmio & Diclorometano \\
\hline Aroeira (caule) & $<$ LD & 240,0 & $<$ LD \\
Graviola (caule) & LD & 258,0 & $<$ LD \\
Jenipapo (caule) & LLD & 240,0 & $<$ LD \\
Mandioca (caule) & LLD & 359,0 & $<$ LD \\
Milho (folha) & LD & 358,5 & $<$ LD \\
Milho (caule I) & LD & 343,3 & $<$ LD \\
Milho (caule II) & LD & 238,2 & $<$ LD \\
Vinagreira (caule) & LD & 284,0 & $<$ LD \\
\hline
\end{tabular}

Onde: LD = Limite de Detecção.

Foram obtidos as espécies Aspergillus níger e Penicillium italicum. No crescimento vegetativo, todos os isolados apresentaram crescimento mediano, atingindo $10 \mathrm{~cm}$ de diâmetro no intervalo de 4 a 8 dias. Os estudos de controle antimicrobiano de Fusarium oxysporum revelaram que os resultados obtidos com o solvente clorofórmio apresentou capacidade inibitória in vitro, apresentando halos de inibiação maiores, proveniente do caule do milho II e do jenipapo, com diâmetro de $13 \mathrm{~mm}$ e $11 \mathrm{~mm}$, respectivamente. 
Extratos de fungos endofíticos isolados do caule do milho e do jenipapo podem ser uma alternativa promissora para o controle biológico de Fusarium oxysporum f. sp. lycopersici.

\section{REFERÊNCIAS}

BARNETT, H. L.; HUNTER, B. B. Ilustrated genera of imperfect fungi. Minnesota: American Phytopathology Society, 1999, 218 p.

CARVALHO, G. A.; REIS, R. P.; MORAES, J. C.; FUINI, L. C.; ROCHA, L. C. D.; GOUSSAIN, M. M. Efeitos de alguns inseticidas utilizados na cultura do tomateiro (Lycopresicon esculentum Mill.) sobre Trichograma pretiosum Riley, 1879 (Hymenoptera: Trichogrammatidae). Ciênc. Agrotec, Lavras, v. 26, n. 6, Novdez, p. 1160-1166. 2002.

CLAY, K.; SCHARDL, C. Evolutionary origins and ecological consequences of endophytes symbiosis with grasses. American Naturalist, v. 160, p.99 - 127. 2002.

FELIZARDO, V. de O. Isolamento e identificação de fungos endófitos presentes em arnica mineira (Lychnophora pinaster Mart.). 2005. 33 f. Monografia (Graduação em Ciências Biológicas Licenciatura) - Centro Universitário de Lavras, Lavras, 2005.
FERNANDES, A. A.; MARTINEZ, H. E. P.; SILVA, D. J. H. da; BARBOSA, J. G.; PEDROSA, A. W. Cultivo sucessivo de plantas de tomate oriundas de sementes e propagação vegetativa em sistema hidropônico. Pesquisa Agropecuária, Brasília, v.42, n.7, p. 1013- 1019, jul. 2007. KUNOH, H. Endophytic actinomycetes: attractive biocontrol agents. Journal of General Plant Pathology, v.68, p.249252. 2002.

KUROZAWA, C.; PAVAN, M. A. P. Doenças do tomateiro. In: KIMATI, H.; BERGAMIN FILHO, A.; CAMARGO, L. E. A.; REZENDE, J. A. M. Manual de Fitopatologia: doenças de plantas cultivadas. v. 2. São Paulo: Ed. Ceres, 2005. p. 690-719.

LOPES, C. A.; SANTOS, J. R. M. Doenças do tomateiro. Brasília: EMBRAPA-CNPH/SPI, 1994. 67p.

MARIANO, R. L. R. Métodos de seleção in vitro para o controle microbiológico de patógenos de plantas. Revisão Anual de Patologia de Plantas, v. I, p. 369- 409, 1993.

NCCLS. National Committee for Clinical Laboratory Standards. Methods for dilution antimicrobial susceptibility tests for fungi that grow aerobically, approved standard. 15 ed., v. 20, n. 2, 33 p., 2002. 
SOUZA, A. Q. L. de; SOUZA, A. D. L. de; ASTOLFI FILHO, S.BELÉM PINHEIRO, M. L.; SARQUIS, M. I. M.; PEREIRA, J. O. Atividade antimicrobiana de fungos endofíticos isolados de plantas tóxicas da amazônia: Palicourea longiflora (Aubl.) Rich e Strychnos cogens Bentham. Acta Amazonica, v. 34, n. 2, p. 185-195, 2004. 